\title{
Adubação orgânica na linha de semeadura no desenvolvimento e produtividade do milho
}

\section{Organic fertilizer in the line sowing in maize growth and yield}

\author{
Leandro Lopes Cancellieri*; Flávio Sérgio Afférri²; Gentil Cavalheiro Adorian³; \\ Hugo Valério Moreira Rodrigues²; Aurélio Vaz de Melo²; Luiz Paulo Miranda \\ Pires $^{4}$; Eduardo Lopes Cancellier ${ }^{2}$
}

\begin{abstract}
Resumo
O uso combinado de fertilizantes químicos e materiais orgânicos têm sido recomendados como manejo alternativo, possibilitando a manutenção de altas produtividades com estabilidade de produção. Este trabalho teve como objetivo avaliar a influência de diferentes doses de esterco bovino aplicados na linha de semeadura, com e sem aplicação de nitrogênio em cobertura, no desenvolvimento e produtividade do milho. O experimento foi instalado no Campus experimental da UFT em Gurupi - TO, no dia seis de março de 2009. O delineamento experimental foi em blocos ao acaso em esquema fatorial $7 \times 2+1$, utilizando-se sete doses de esterco $\left(0,0 ; 10,0 ; 20,0 ; 30,0 ; 40,0 ; 50,0\right.$ e 60,0 t ha- $\left.{ }^{-1}\right)$ e um tratamento químico testemunha e como segundo fator duas doses de nitrogênio em cobertura. Foram realizadas avaliações semanais de altura de plantas dos 15 aos 57 dias após a emergência. Foram avaliadas altura de plantas final, massa verde e produtividade de grãos. As maiores doses de esterco promovem aumentos significativos nas características avaliadas. O nitrogênio em cobertura promoveu aumentos nas taxas de crescimento de plantas, na produção de massa verde e altura final de plantas, mesmo com adição de adubação orgânica. A aplicação de $50 \mathrm{t} \mathrm{ha}^{-1}$ de esterco sem aplicação de cobertura resultou em produtividade equivalente à adubação química, enquanto com aplicação de $\mathrm{N}$ em cobertura a dose de esterco equivalente foi 45,4 t ha-1. Quando não se aplicou adubação nitrogenada em cobertura, a adubação química produziu massa verde e grãos equivalente as maiores doses de esterco, porém na aplicação de $\mathrm{N}$ em cobertura as maiores doses de esterco proporcionaram produtividades superiores a adubação química.
\end{abstract}

Palavras-chave: Zea mays. Manejo orgânico. Adubação. Massa verde.

\begin{abstract}
The combined use of chemical fertilizers and organic materials have been recommended as alternative management, enabling the maintenance of high yields and stability. This study aimed to evaluate the influence of levels of manure applied in the row, with and without nitrogen topdressing application, in maize growth and yield. The experiment was carried out in Gurupi - TO, on March 6, 2009. The experimental design was randomized blocks in factorial scheme $7 \times 2+1$, where were used seven levels of
\end{abstract}

1 Doutorando do curso de Pós-Graduação em Agronomia, Fitotecnia da Universidade Federal de Lavras, Bolsista CAPES, UFLA, Lavras, MG, Brasil, Cx. Postal: 3037, CEP: 37200-000. E-mail: leandrocancellier@gmail.com

2 Universidade Federal do Tocantins, Campus de Gurupi, Caixa Postal 66, CEP: 77402-970, Gurupi, TO, Brasil. E-mail: flavio@, uft.edu.br; hugo_gabi@yahoo.com.br; vazdemelo@uft.edu.br; educancellier@hotmail.com

3 Doutorando do curso de Pós-Graduação em Fitotecnia da Universidade de São Paulo, USP/ESALQ, Piracicaba-SP, Brasil, CEP 13418-900. E-mail: gentil_cavalheiro@hotmail.com

4 Mestrando do curso de Pós-Graduação em Genética e Melhoramento de plantas da Universidade Federal de Lavras, UFLA, Lavras-MG, Brasil, Cx. Postal: 3037, CEP: 37200-000. E-mail: luizpaulo_vortex@hotmail.com

* Autor para correspondência

Recebido para publicação 13/11/2009 Aprovado em 13/04/2011 
manure $\left(0.0 ; 10.0 ; 20.0 ; 30.0 ; 40.0 ; 50.0\right.$ and $\left.60.0 \mathrm{tha}^{-1}\right)$ and one treatment with chemical fertilizer and the second factor were two levels of nitrogen topdressing. Were evaluated plant height weekly, from 15 to 57 days after emergency. Were evaluated final plant height, green matter and grain yield. The highest levels of manure led to significant increases in the evaluated characteristics. Nitrogen topdressing promoted increase in grown rate, green mass and final plant height, even with the addition of manure. The manure application of $50 \mathrm{t} \mathrm{ha}^{-1}$ without nitrogen topdressing showed equivalent yield to chemical fertilizer, yet, with application of nitrogen topdressing in the equivalent manure level was $45.4 \mathrm{tha}^{-1}$. When wasn't applied nitrogen topdressing, the chemical fertilizer yielded equivalent grains and green mass as the highest level of manure, however, in the treatment with topdressing the highest levels of manure led to higher yields than the chemical fertilizer.

Key words: Zea mays. Organic management. Fertilization. Green matter.

\section{Introdução}

O milho é um dos principais cereais produzidos no Brasil, cultivado em cerca de 14 milhões de hectares, com produção de aproximadamente 58,6 milhões de toneladas de grãos e produtividade média de 4,2 toneladas por hectare (CONAB, 2009).

No estado de Tocantins, o cultivo de milho constitui-se em uma das principais atividades agrícolas e abrange diversos seguimentos de produtores e condições ambientais (MORELLO et al., 2002), inclusive áreas com algum nível de estresse abiótico, principalmente nutricionais (CANCELLIER et al., 2011). A área cultivada estimada para safra de 2008/2009 foi de 83,9 mil hectares, produção de 268,2 mil toneladas e produtividade de 3,2 toneladas por hectare, valor este que está abaixo da média nacional, 3,5 toneladas por hectare (CONAB, 2009).

A importância econômica do milho é caracterizada pelas diversas formas de sua utilização, que vai desde a alimentação animal até a indústria de alta tecnologia. Na realidade, o uso do milho em grão para alimentação animal representa a maior parte do consumo desse cereal, isto é, cerca de 70\% no mundo. Nos Estados Unidos cerca de $50 \%$ é destinado a alimentação animal, enquanto no Brasil varia de 60 a 80\% (DUARTE, 2008).

Nos trópicos, incluindo o estado de Tocantins, estresses abióticos são comuns em praticamente todas as regiões de cultivo do milho, em especial a deficiência de nitrogênio no solo, que para o milho é fator limitante para que se alcance boas produtividades, influenciando o crescimento da planta mais do que qualquer outro nutriente (BÄNZIGER; EDMEADES; LAFITTE， 1999; BREDEMEIER; MUNDSTOCK, 2000).

O milho é uma das culturas mais exigentes em fertilizantes, especialmente os nitrogenados. O suprimento inadequado de nitrogênio é considerado um dos principais fatores limitantes ao rendimento de grãos do milho, pois o $\mathrm{N}$ exerce importante função nos processos bioquímicos da planta. Ele é constituinte de proteínas, enzimas, coenzimas, ácidos nucleícos, fitocromos e da clorofila (CANTARELLA, 1993).

Segundo Meneses (1993), vários tipos de adubos orgânicos são capazes de incrementar o rendimento de grãos na cultura do milho, incluindo o esterco bovino. Além do mais, o esterco bovino também aumenta o rendimento da parte aérea da planta do milho cultivado para silagem (TRAN; N'DAYEGAMIYE, 1995).

Em condições tropicais, são requeridas cerca de 7 e 10 t ha $^{-1}$ ano $^{-1}$ de resíduos com elevada e baixa relação $\mathrm{C}: \mathrm{N}$, respectivamente, para manter o teor de $\mathrm{C}$ orgânico total no solo em 1 dag $\mathrm{kg}^{-1}$ (LEITE et al., 2003).

A adição de materiais orgânicos é fundamental à qualidade do solo, caracterizando-se pela liberação gradativa de nutrientes, que reduz processos como lixiviação, fixação e volatilização, embora dependam essencialmente da taxa de decomposição, controlada pela temperatura, umidade, textura e mineralogia do solo, além da composição química 
do material orgânico utilizado (LEITE et al., 2003).

Além do fornecimento de nitrogênio, a matéria orgânica, por sua vez, promove a retenção de cátions e fornecimento de nutrientes (SILVA et al., 2004). Além do mais, desempenha outras funções como melhoria da estrutura, agregação, descompactação, aeração e o aumento da atividade biológica (ZHANG; HARTGE; RINGE, 1997; OELSEN; MOLDRUP; HENRIKSEN, 1997). Desse modo, a matéria orgânica influencia o crescimento dos vegetais, o que torna o seu incremento importante para a agricultura (STEVENSON, 1982).

O uso combinado de fertilizantes químicos e materiais orgânicos têm sido recomendados como manejo alternativo, possibilitando a manutenção de alta produtividade, com estabilidade de produção, principalmente quando o material orgânico aplicado apresenta elevada relação $\mathrm{C}: \mathrm{N}$ e elevados conteúdos de lignina e polifenóis, e para regiões onde o uso de fertilizante é recomendado (FERNANDES et al., 1997).

O esterco parece causar imobilização de nutrientes do solo no primeiro mês após sua incorporação. Depois desse período, a liberação de nutrientes aumenta progressivamente, atingindo as maiores quantidades entre três e seis meses após a incorporação (SAMPAIO; OLIVEIRA; NASCIMENTO, 2007).

Neste contexto, o trabalho teve como objetivo avaliar a influência de diferentes doses de esterco bovino aplicados na linha de semeadura, com e sem aplicação de nitrogênio em cobertura, no desenvolvimento e produtividade do milho.

\section{Material e Métodos}

O experimento foi conduzido na Estação Experimental do Campus Universitário de Gurupi, pertencente à Universidade Federal do Tocantins (UFT). O preparo do solo para a instalação foi realizado através de sistema convencional, com uma gradagem e nivelamento do solo.
A variedade de milho BR 106 foi semeada no dia 6 de março de 2009 utilizando o delineamento experimental de blocos ao acaso em arranjo fatorial $7 \times 2+1$ com três repetições. Faram avaliadas oito doses de adubação de semeadura, sendo sete com esterco bovino curtido aplicado na linha de plantio, variando entre 0,$0 ; 10,0 ; 20,0 ; 30,0 ; 40,0 ; 50,0$ e $60,0 \mathrm{t}$ ha $^{-1}$, e uma adubação química como testemunha (600 $\mathrm{kg} \mathrm{ha}^{-1}$ da formula 4-14-8 de NPK), e como segundo fator duas doses de nitrogênio em cobertura $(80 \mathrm{~kg}$ ha $^{-1}$ de $\mathrm{N}$ e sem adubação de cobertura), aplicados aos 30 dias após a emergência usando como fonte a uréia. Aos 14 dias após a emergência foi realizado um desbaste para se obter uma população de 55 mil plantas ha ${ }^{-1}$, sendo utilizado para as avaliações dez plantas competitivas da parcela tomadas ao acaso.

A análise química do esterco utilizado no experimento teve seus teores de $\mathrm{Ca}-\mathrm{Mg}-$ $\mathrm{H}^{+} \mathrm{Al}$ e CTC Total de 4 - 2,3 - 0,4 e $7 \mathrm{cmol}_{\mathrm{c}} \mathrm{dm}^{-3}$ respectivamente, $\mathrm{Ke}$ e com 103 e 683 ppm, saturação de bases de $94,0 \%$ e 7,3\% de matéria orgânica. A análise química do solo onde o experimento foi implantado foi a seguinte: $\mathrm{pH}$ em $\mathrm{H}_{2} \mathrm{O}$ de 5,2, Ca e $\mathrm{Mg}$ com 2,1 e 0,4 $\mathrm{cmol}_{\mathrm{c}} \mathrm{dm}^{-3}$ respectivamente, $\mathrm{P}$ e $\mathrm{K}$ com 5 e $18 \mathrm{mg} \mathrm{dm}^{-3}$ e 2,1\% de matéria orgânica.

Foram avaliadas: o crescimento semanal da altura de plantas, dos 15 aos 57 dias após a emergência. A altura de plantas final que foi medida a partir do solo até a inserção da folha bandeira em cm; a massa verde total da planta foi obtida pelo peso de plantas da parcela e extrapolado a $\mathrm{t} \mathrm{ha}^{-1} \mathrm{e}$; a produtividade de grãos foi obtida pelo peso de uma amostra de dez plantas competitivas da parcela tomadas ao acaso e convertendo seus valores para $\mathrm{kg} \mathrm{ha}^{-1}$ corrigido para $13 \%$ de umidade.

Os dados das avaliações semanais de altura de plantas foram submetidos à análise de regressão individualmente para cada dose de esterco e condição de adubação em cobertura em função das épocas de avaliação. A produtividade, massa verde e altura de plantas final foram submetidas à análise de regressão em função das doses de esterco 
e para comparação dos tratamentos orgânicos com o químico foi realizado o contraste.

\section{Resultados e Discussão}

A análise de variância das regressões (Tabela
1) do crescimento do milho nas diferentes doses de esterco bovino nas duas condições de adubação nitrogenada em cobertura mostra altos valores de $\mathrm{F}$ para todos os tratamentos, indicando significância a $1 \%$ para todas as regressões.

Tabela 1. Resumo da análise de variância das regressões ajustadas para as doses de adubação com esterco, com e sem adubação nitrogenada em cobertura em sete avaliações semanais no município de Gurupi, TO, maio de 2009.

\begin{tabular}{|c|c|c|c|c|c|c|c|c|c|c|}
\hline \multirow[t]{2}{*}{$\overline{\mathbf{F V}}$} & \multirow[t]{2}{*}{ G L } & \multirow[t]{2}{*}{$\mathrm{N}$ em cobertura } & \multicolumn{8}{|c|}{ Dose de esterco $\left(\mathrm{t} \mathrm{ha}^{-1}\right)$} \\
\hline & & & $\mathbf{0}$ & 10 & 20 & 30 & 40 & 50 & 60 & Químico \\
\hline \multirow[t]{2}{*}{ Regressão } & 1 & $80 \mathrm{~kg} \mathrm{ha}^{-1}$ & 20780,8 & 21030,4 & 20442,6 & 23162,9 & 22710,7 & 25557,2 & 24424 , & 123792,2 \\
\hline & & $0 \mathrm{~kg} \mathrm{ha}^{-1}$ & 12185,7 & 17605,1 & 14938 & 15815,9 & 20663,3 & 18789,5 & 19337 & 520487,6 \\
\hline \multirow[t]{4}{*}{ Teste F } & - & $80 \mathrm{~kg} \mathrm{ha}^{-1}$ & 151,6 & 163,8 & 183,6 & 169,3 & 155,6 & 132,1 & 183,2 & 172,1 \\
\hline & & Prob & $* *$ & $* *$ & $* *$ & $* *$ & $* *$ & $* *$ & $* *$ & $* *$ \\
\hline & & $0 \mathrm{~kg} \mathrm{ha}^{-1}$ & 298,8 & 175,6 & 228,3 & 152,6 & 260,2 & 304,3 & 199,7 & 194,9 \\
\hline & & Prob & $* *$ & $* *$ & $* *$ & $* *$ & $* *$ & $* *$ & $* *$ & $* *$ \\
\hline \multirow[t]{2}{*}{ Residual } & 5 & $80 \mathrm{~kg} \mathrm{ha}^{-1}$ & 137,0 & 128,4 & 111,3 & 136,8 & 145,9 & 193,5 & 133,3 & 138,2 \\
\hline & & $0 \mathrm{~kg} \mathrm{ha}^{-1}$ & 40,77 & 100,2 & 65,4 & 103,6 & 79,4 & 61,7 & 96,8 & 105,1 \\
\hline \multirow[t]{2}{*}{ Total } & 6 & $80 \mathrm{~kg} \mathrm{ha}^{-1}$ & 3577,6 & 3612,1 & 3499,8 & 3974,5 & 3906,7 & 4420,7 & 4181,7 & 4080,5 \\
\hline & & $0 \mathrm{~kg} \mathrm{ha}^{-1}$ & 2064,9 & 3017,7 & 2544,2 & 2722,3 & 3510,1 & 3183,0 & 3303,6 & 3502,2 \\
\hline
\end{tabular}

Obs.: ** significativo a $1 \%$ pelo teste $\mathrm{F}$ da regressão.

As regressões (Tabela 2) revelaram efeito probabilidade pelo teste F), indicando que o modelo positivo e linear de todas as doses de esterco linear explica em média $97 \%$ do crescimento da nas duas condições de nitrogênio em cobertura altura de plantas nas doses de esterco. no crescimento da altura de plantas $(1 \%$ de

Tabela 2. Valores médios para altura de planta do coeficiente de regressão $(\beta)$, coeficiente linear $(\alpha)$ e coeficiente de determinação $\left(\mathrm{R}^{2}\right)$ da regressão linear em diferentes doses de adubação com esterco, com e sem adubação nitrogenada em cobertura em sete avaliações semanais no município de Gurupi, TO, maio de 2009.

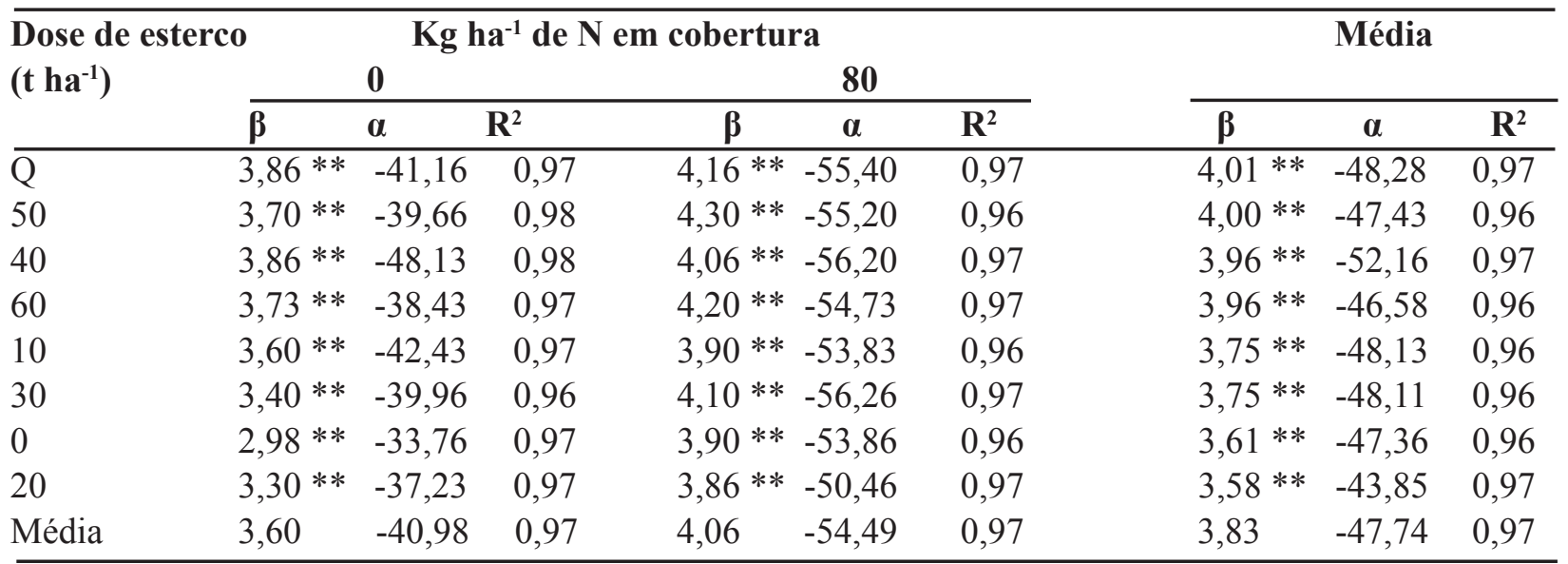

Obs.: ** significativo a $1 \%$ pelo teste $\mathrm{F}$ da regressão. 
Observa-se também que houve uma tendência das maiores doses de esterco apresentarem os maiores valores do coeficiente de regressão juntamente com a adubação química.

A dose de 0,0 t ha ${ }^{-1}$ de esterco foi a que promoveu maior diferença entre com e sem cobertura, no crescimento de plantas, sendo que na ausência da adubação nitrogenada em cobertura o crescimento foi de $2,98 \mathrm{~cm} \mathrm{dia}^{-1}$, enquanto com a aplicação de $80,0 \mathrm{~kg} \mathrm{ha}^{-1} \mathrm{de} \mathrm{N}^{-} \mathrm{m}$ cobertura houve um crescimento diário de 3,90 $\mathrm{cm}$. Crescimento semelhante é observado para a dose de 40,0 tha ${ }^{-1}$ de esterco e para a adubação química que apresentaram as maiores taxas de crescimento na ausência de adubação em cobertura, indicando que para obter a mesma taxa de crescimento na substituição da aplicação de $\mathrm{N}$ em cobertura, se faz necessário a aplicação de $40 \mathrm{t}$ $\mathrm{ha}^{-1}$ de esterco na semeadura. Já quando se compara as doses 0,0 e 40,0 $\mathrm{t} \mathrm{ha}^{-1}$ de esterco com a aplicação de $80 \mathrm{~kg} \mathrm{ha}^{-1}$ de $\mathrm{N}$ em cobertura, observa-se apenas diferença na taxa de crescimento de 3,90 a 4,06 $\mathrm{cm} \mathrm{dia}^{-1}$, indicando que o nitrogênio em cobertura contribui mais para o crescimento diário de plantas do que a aplicação de 40,0 t ha $\mathrm{t}^{-1}$ de esterco.

O tratamento com dose 50,0 tha ${ }^{-1}$ de esterco com nitrogênio em cobertura apresentou maior valor do coeficiente de regressão, indicando que as plantas apresentaram maior crescimento diário nesta dose, ou seja, 4,30 cm. Fidelis et al. (2007) observaram que a maior dose de nitrogênio em cobertura $(120,0$ $\left.\mathrm{kg} \mathrm{ha}{ }^{-1}\right)$ proporcionou maiores alturas de plantas de milho em relação à menor dose $\left(20,0 \mathrm{~kg} \mathrm{ha}^{-1}\right)$. No presente trabalho os tratamentos com dose de esterco quando adubados com $\mathrm{N}$ em cobertura, aplicando o modelo de regressão, apresentaram $176,9 \mathrm{~cm}$ na última avaliação (57 DAE), e para as doses de esterco que não receberam adubação de $\mathrm{N}$ em cobertura, apresentaram 164,2 cm.

Considerando as médias dos tratamentos adubados com esterco, o tratamento químico apresentou o maior coeficiente de regressão $(4,01)$. Este valor mostra que, para este tratamento, a planta cresceu $4,01 \mathrm{~cm} \mathrm{dia}^{-1}$. Os altos valores do coeficiente de determinação $\left(\mathrm{R}^{2}\right)$, comprovam que a equação linear é adequada para prever a resposta do crescimento de planta em relação aos tratamentos utilizados. Silva et al. (2004) avaliando doses de esterco em cultivar de milho, observaram crescimento linear para altura de planta na cultivar AG-9012. A adoção de práticas de manejo que visem posicionar a cultura em situação competitiva vantajosa em relação às plantas daninhas, constituise em alternativa viável para reduzir, ou até eliminar a utilização de herbicidas.

Begna et al. (2001) afirmam que um rápido desenvolvimento da cultura proporciona vantagens competitiva com plantas daninhas, reduzindo perdas da cultura por competição. Elevado vigor de plântulas, emergência precoce, rápida expansão foliar e elevada estatura de plantas são consideradas as principais características de planta que proporcionam vantagens competitivas com plantas daninhas (BALBINOT JÚNIOR; FLECK, 2005).

Alterações nas relações de competição por água, luz e nutrientes entre o milho e as plantas daninhas, em favor da cultura, podem ser alcançadas por meio de práticas de manejo (BALBINOT JÚNIOR; FLECK, 2005). Acredita-se que uma delas pode ser a aplicação da adubação na linha de semeadura, inclusive a orgânica que pode suprimir o desenvolvimento de plantas daninhas pela diminuição da disponibilidade de recursos às mesmas $\mathrm{e}$, consequentemente, resultando em plantas mais bem nutridas e vigorosas, com maior potencial produtivo.

Pela análise de variância (Tabela 3) a altura de plantas final não foi influenciada pelas doses de esterco, porém sofreu influência pela aplicação de $\mathrm{N}$ em cobertura a $1 \%$ de probabilidade pelo teste F. Observa-se efeito inverso para a produtividade, que apresentou diferença significativa apenas para as doses de esterco, não sendo influenciada pela aplicação de $\mathrm{N}$ em cobertura. 
Tabela 3. Resumo da análise de variância para altura de planta (AP), produtividade (PROD) e massa verde (MV) no município de Gurupi, TO, maio de 2009.

\begin{tabular}{llll}
\hline \multicolumn{1}{c}{ F.V. } & \multicolumn{3}{c}{ Quadrado médio } \\
& AP & PROD & MV \\
\hline Nitrogênio & $1513,1^{* *}$ & 115,63 & $176,71^{* *}$ \\
Doses de esterco & 247,500 & $692125^{* *}$ & $51,12^{* *}$ \\
Doses X N & 79,000 & 57930,35 & 19,04 \\
Bloco & 1863,700 & 516224,86 & 78,18 \\
Erro & 146,300 & 170503,56 & 11,22 \\
C.V. $\%$ & 7,1 & 18,87 & 13,76 \\
\hline
\end{tabular}

Obs.: ** significativo a $1 \%$ pelo teste $\mathrm{F}$.

A massa verde foi influenciada significativamente a $1 \%$ de probabilidade pelo teste $\mathrm{F}$ para as doses de esterco e para a adubação nitrogenada em cobertura, porém a interação não foi significativa assim como para altura de planta e produtividade.

A altura de planta (Figura 1) apresenta efeito linear significativo a $1 \%$ de probabilidade pelo teste $\mathrm{F}$, juntamente com valores do coeficiente de determinação alto indica que é possível explicar a altura de plantas em função das doses de esterco bovino aplicada. A taxa do crescimento de plantas em função da adubação com esterco bovino onde houve aplicação de $\mathrm{N}$ em cobertura foi $0,2688 \mathrm{~cm}$ a cada tonelada de esterco aplicada a partir da altura de planta de $168 \mathrm{~cm}$ que corresponde a ausência de esterco bovino aplicado, enquanto onde não houve aplicação nitrogenada em cobertura a taxa de crescimento da altura de plantas a partir da dose 0,0 $\mathrm{t}$ de esterco que corresponde a $151,8 \mathrm{~cm}$ foi de 0,3254 $\mathrm{cm}$ por tonelada de esterco aplicado, indicando que a ausência de aplicação de $\mathrm{N}$ em cobertura proporciona maiores taxas de aumento de plantas mesmo não apresentando maiores altura de planta final.

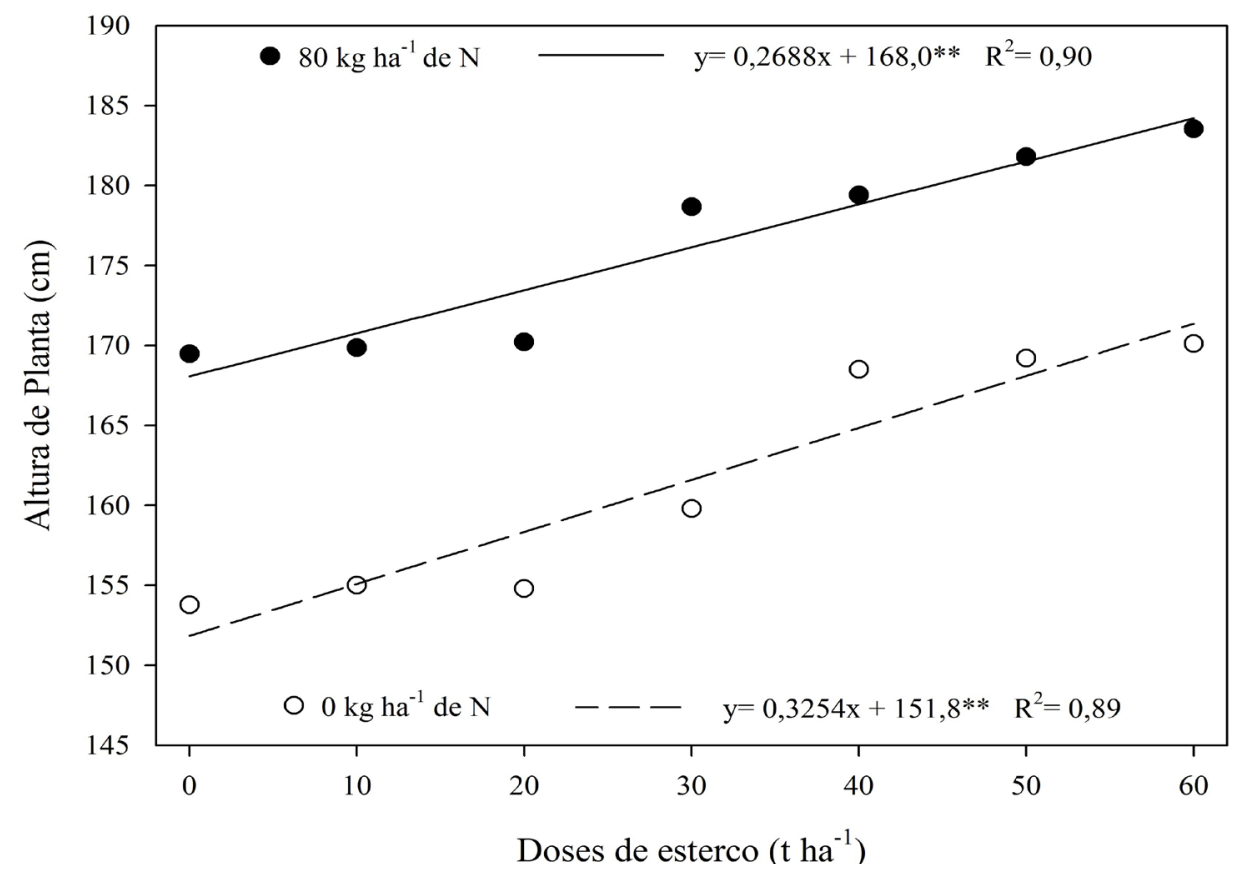

Figura 1. Regressão dos valores médios de altura de plantas $(\mathrm{cm})$ em diferentes doses de adubação com esterco, com e sem adubação nitrogenada em cobertura em Gurupi - TO, maio de 2009. 
Observa-se que a regressão linear da massa verde (Figura 2) apresentou significância a 5\% pelo teste $\mathrm{F}$ nas doses onde se aplicou $80 \mathrm{~kg} \mathrm{ha}^{-1} \mathrm{de} \mathrm{N}$ em cobertura, com uma taxa de incremento de $0,103 \mathrm{t}$ de massa verde a cada tonelada de esterco bovino aplicado na linha de semeadura a partir da produção de $23,8 \mathrm{t} \mathrm{ha}^{-1}$ de massa verde que corresponde a produção de massa verde sem a aplicação de esterco.

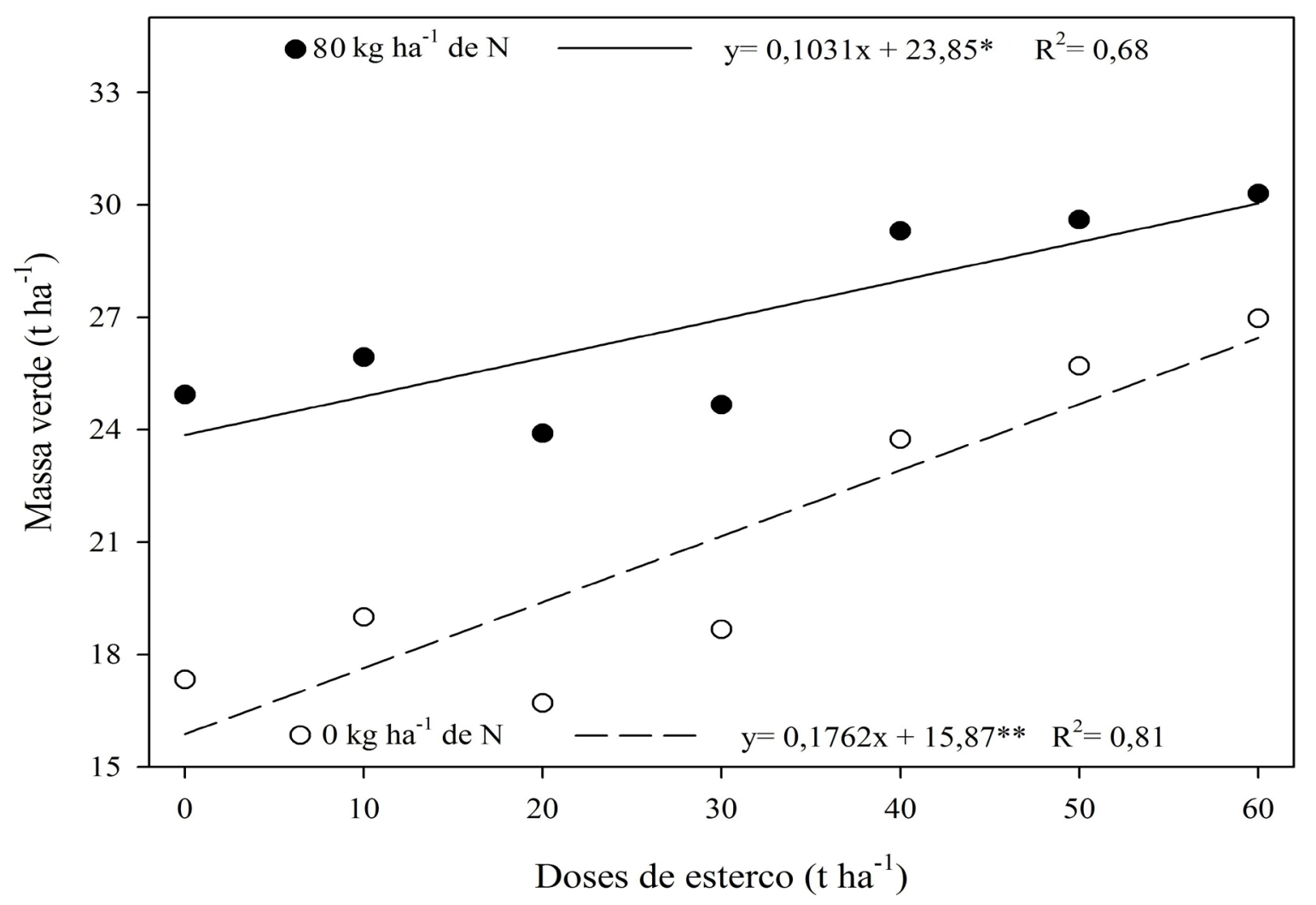

Figura 2. Regressão dos valores médios de massa verde $\left(\mathrm{t} \mathrm{ha}^{-1}\right)$ em diferentes doses de adubação com esterco, com e sem adubação nitrogenada em cobertura em Gurupi - TO, maio de 2009.

Já para as doses de esterco sem a aplicação de $\mathrm{N}$ apresentou taxa de incremento de $0,176 \mathrm{t}$ de massa verde para cada tonelada de esterco bovino aplicado, 58\% superior quando comparado com a aplicação de cobertura, sendo ainda significante a $1 \%$ pelo teste $\mathrm{F}$.

Segundo Fageria, Santos e Stone (2003), o nitrogênio é componente da clorofila que aumenta a área foliar da planta que aumenta a eficiência de interceptação da radiação solar e a taxa fotossintética e consequentemente maior massa verde da planta, justificando maiores produção de massa verde onde ocorreu a aplicação de $80 \mathrm{~kg} \mathrm{ha}^{-1}$ de $\mathrm{N}$ em cobertura.

A menor taxa de incremento da massa verde com o aumento das doses de esterco, onde houve adubação de $\mathrm{N}$ em cobertura, é atribuída ao fato de que o nitrogênio supriu a necessidade da planta, mesmo nas menores doses de esterco. O esterco mesmo apresentando este nutriente, não poderia substituir a aplicação de $\mathrm{N}$, pois disponibiliza os nutrientes de forma lenta e gradual, onde para uma cultura de ciclo relativamente rápido e de grande exigência nutricional como o milho, seria um fator limitante.

Melo, Nornberg e Rocha (2004) obtiveram na média de dois híbridos de milho uma produção de $20,8 \mathrm{t} \mathrm{ha}^{-1}$ de massa verde total, não observando diferença significativa entre os mesmos. Valor inferior ao encontrado neste trabalho, no qual a massa verde total sem adubação com esterco e com aplicação de $80 \mathrm{~kg} \mathrm{ha}^{-1}$ de $\mathrm{N}$ em cobertura foi 23,85 $\mathrm{t} \mathrm{ha}^{-1}, 14,6 \%$ superior. 
Os autores afirmam que uma baixa produção de massa verde se deve principalmente à menor estatura das plantas, o que é observado neste trabalho, onde, na média, as menores doses de esterco proporcionaram as menores alturas de plantas, resultando em menor produção de massa verde total da planta.

Em relação à produtividade (Figura 3) observase que para as doses de esterco sem adubação nitrogenada em cobertura a taxa de incremento de produção foi de $17,65 \mathrm{~kg}$ de grãos para cada tonelada de esterco aplicado. Já onde houve aplicação de N em cobertura a taxa de incremento na produtividade foi de $14,76 \mathrm{~kg}$, observando assim que a adubação nitrogenada contribui menos para o aumento da produtividade quando há interação entre adubação orgânica e mineral, efeito este também observado por Maia e Cantarutti, (2004). Silva et al. (2007) afirmam que o uso contínuo da adubação organomineral na cultura do milho, provoca aumentos significativos por vários anos na produção de grãos.

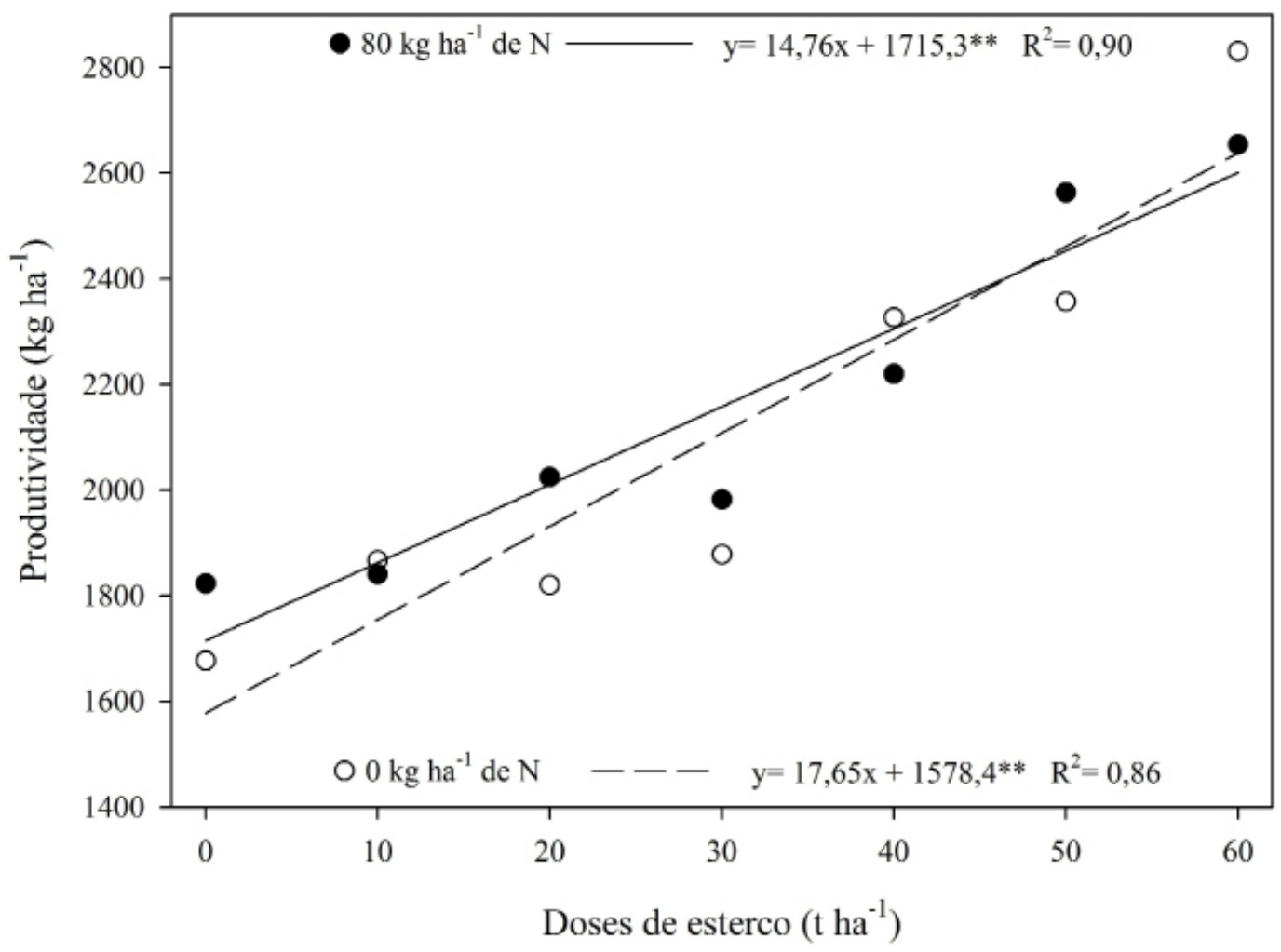

Figura 3. Regressão dos valores médios de produtividade $\left(\mathrm{kg} \mathrm{ha}^{-1}\right)$ em diferentes doses de adubação com esterco, com e sem adubação nitrogenada em cobertura em Gurupi - TO, maio de 2009.

As regressões tanto com adubação nitrogenada em cobertura quanto sem cobertura apresentaram significância a $1 \%$ de probabilidade pelo teste $\mathrm{F}$ e também apresentam um coeficiente de determinação alto, 0,90 e 0,86 respectivamente, indicando que a equação linear é adequada para prever o aumento da produtividade conforme o aumento das doses de esterco.

Pela comparação entre os contrastes (Tabela 4), observa-se que para a altura de plantas não houve diferença significativa para nenhum contraste das doses de esterco com a adubação química. Houve, porém, diferença significativa a $1 \%$ pelo teste $\mathrm{F}$ para o contraste entre com e sem adubação nitrogenada em cobertura, sendo este contraste também diferente significativamente para a massa verde, sendo que este efeito pode ser observado claramente pela distância das 
regressões nas condições de com e sem adubação em cobertura nas (Figuras 1 e 2).

Tabela 4. Teste F dos contrastes de altura de planta (AP), produtividade (PROD) e massa verde (MV) no município de Gurupi - TO, maio de 2009.

\begin{tabular}{|c|c|c|c|c|c|c|c|}
\hline \multirow[t]{2}{*}{ Testemunha } & \multirow[t]{2}{*}{ t ha ${ }^{-1}$ de esterco } & \multicolumn{2}{|c|}{$\overline{\mathbf{A P}}$} & \multicolumn{2}{|c|}{ PROD } & \multicolumn{2}{|c|}{ MV } \\
\hline & & \multicolumn{2}{|c|}{$0 \mathrm{~kg} \mathrm{ha}^{-1} 80 \mathrm{~kg} \mathrm{ha}^{-1}$} & 0 kg ha $\mathbf{~}^{-1}$ & 80 kg ha $^{-1}$ & 0 kg ha $\mathbf{~}^{-1}$ & $80 \mathrm{~kg} \mathrm{ha}^{-1}$ \\
\hline & $\begin{array}{l}0,10,20,30 \\
40,50 \text { e } 60\end{array}$ & $1,43^{\mathrm{ns}}$ & $1,06^{\mathrm{ns}}$ & $2,46^{\mathrm{ns}}$ & $1,03^{\mathrm{ns}}$ & $6,71 *$ & $1,65^{\mathrm{ns}}$ \\
\hline & $0,10,20$ e 30 & $3,44^{\mathrm{ns}}$ & $2,22^{\mathrm{ns}}$ & $7,60 * *$ & $3,95^{\mathrm{ns}}$ & $14,99 * *$ & $0,10^{\mathrm{ns}}$ \\
\hline & $30,40,50$ e 60 & $0,24^{\mathrm{ns}}$ & $0,16^{\mathrm{ns}}$ & $0,23^{\mathrm{ns}}$ & $0,02^{\mathrm{ns}}$ & $1,82^{\mathrm{ns}}$ & $3,55^{\mathrm{ns}}$ \\
\hline & 0 e 10 & $3,42^{\mathrm{ns}}$ & $2,69^{\mathrm{ns}}$ & $7,10^{*}$ & $4,60 *$ & $11,83 * *$ & $0,27^{\mathrm{ns}}$ \\
\hline & 10 e 20 & $3,21^{\mathrm{ns}}$ & $2,49^{\mathrm{ns}}$ & $5,70 *$ & $3,08^{\mathrm{ns}}$ & $12,70 * *$ & $0,10^{\mathrm{ns}}$ \\
\hline \multirow{2}{*}{$\begin{array}{l}\text { Adubação } \\
\text { química }\end{array}$} & 20 e 30 & $2,36^{\mathrm{ns}}$ & $1,16^{\mathrm{ns}}$ & $5,60 *$ & $2,20^{\mathrm{ns}}$ & $13,17 * *$ & $0,005^{\mathrm{ns}}$ \\
\hline & 30 e 40 & $0,57^{\mathrm{ns}}$ & $0,33^{\mathrm{ns}}$ & $1,93^{\mathrm{ns}}$ & $1,22^{\mathrm{ns}}$ & $5,04 *$ & $1,29^{\mathrm{ns}}$ \\
\hline \multirow[t]{9}{*}{ vs. } & 40 e 50 & $0,05^{\mathrm{ns}}$ & $0,16^{\mathrm{ns}}$ & $0,21^{\mathrm{ns}}$ & $0,001^{\mathrm{ns}}$ & $0,73^{\mathrm{ns}}$ & $4,44^{*}$ \\
\hline & 50 e 60 & $0,02^{\mathrm{ns}}$ & $0,03^{\mathrm{ns}}$ & $0,25^{\mathrm{ns}}$ & $0,72^{\mathrm{ns}}$ & $0,05^{\mathrm{ns}}$ & $5,30 *$ \\
\hline & 0 & $2,82^{\mathrm{ns}}$ & $2,07^{\mathrm{ns}}$ & $6,90 *$ & $3,56^{\mathrm{ns}}$ & $10,64 * *$ & $0,08^{\mathrm{ns}}$ \\
\hline & 10 & $2,32^{\mathrm{ns}}$ & $1,96^{\mathrm{ns}}$ & $3,96^{\mathrm{ns}}$ & $3,34^{\mathrm{ns}}$ & $7,26 * *$ & $0,39^{\text {ns }}$ \\
\hline & 20 & $2,49^{\mathrm{ns}}$ & $1,78^{\mathrm{ns}}$ & $4,60 *$ & $1,47^{\mathrm{ns}}$ & $12,10 * *$ & $0,005^{\mathrm{ns}}$ \\
\hline & 30 & $1,18^{\mathrm{ns}}$ & $0,28^{\mathrm{ns}}$ & $3,82^{\mathrm{ns}}$ & $1,84^{\mathrm{ns}}$ & $7,88 * *$ & $0,03^{\mathrm{ns}}$ \\
\hline & 40 & $0,05^{\mathrm{ns}}$ & $0,21^{\mathrm{ns}}$ & $0,20^{\mathrm{ns}}$ & $0,31^{\mathrm{ns}}$ & $1,16^{\mathrm{ns}}$ & $3,14^{\mathrm{ns}}$ \\
\hline & 50 & $0,02^{\mathrm{ns}}$ & $0,05^{\mathrm{ns}}$ & $0,12^{\mathrm{ns}}$ & $0,34^{\mathrm{ns}}$ & $0,16^{\mathrm{ns}}$ & $3,52^{\mathrm{ns}}$ \\
\hline & 60 & $0,01^{\mathrm{ns}}$ & $0,003^{\mathrm{ns}}$ & $1,50^{\mathrm{ns}}$ & $0,79^{\mathrm{ns}}$ & $0,001^{\mathrm{ns}}$ & $4,47^{*}$ \\
\hline Doses de N & & &, $95 * *$ & 0,1 & $6^{\mathrm{ns}}$ & &, $7 * *$ \\
\hline
\end{tabular}

Obs.: * $\mathrm{e}^{* *}$ significativo a 5 e a $1 \%$ respectivamente pelo teste $\mathrm{F}$. ${ }^{\text {ns }}$ não significativo.

A massa verde apresentou diferença significativa a $5 \%$ de probabilidade para os contrastes da adubação química onde não houve adubação nitrogenada em cobertura com todas as doses de esterco e para o contraste com as doses de 30,0 e 40,0 t ha-1. Apresentou ainda diferença significativa a $1 \%$ para comparação de todos os contrastes com as doses de 0,$0 ; 10,0$ e 20,0 t ha- com exceção apenas do contraste com todas as doses de esterco e também para o contraste com a dose de 30,0 tha1, ficando evidente que houve uma tendência nas maiores doses de esterco utilizadas neste trabalho se equivaler à adubação química onde não se aplica $\mathrm{N}$ em cobertura.

Já onde se aplicou $80 \mathrm{~kg} \mathrm{ha}^{-1}$ de $\mathrm{N}$ em cobertura observa-se efeito inverso, sendo que houve uma tendência nos contrastes da adubação química com as menores doses de esterco não apresentarem diferenças significativas, sendo os contrastes 40,0-50,0; 50,0-60,0 e 60,0 t ha- ${ }^{-1}$ com adubação química, serem os únicos a apresentarem diferença significativa a $5 \%$ de probabilidade, indicando que estes são superiores que a adubação química, podendo, portanto utilizar estas doses de esterco bovino em substituição a adubação química para se obter produtividade de massa verde superior.

Para a produtividade observa-se que todos os contrastes realizados com as doses de 40,0; 50,0 e 60,0 $\mathrm{t} \mathrm{ha}^{-1}$ de esterco em ambas as condições de adubação nitrogenada em cobertura não apresentaram diferenças significativas com a adubação química, porém com adubação em cobertura o contraste $0,0-10,0 \mathrm{t} \mathrm{ha}^{-1}$ apresentou diferença a $5 \%$ de probabilidade. Na ausência de adubação de $\mathrm{N}$ em cobertura o contraste 0,010,0-20,0-30,0 apresentou diferença a $1 \%$ de 
probabilidade, já os contrastes $0,0-10,0 ; 10,0-20,0$; 20,0-30,0; 0,0 e 20,0 t ha ${ }^{-1}$ de esterco apresentaram diferenças significativa a 5\%, indicando que a adubação química foi superior quando aplicado as menores doses de esterco, ficando mais evidente quando não há adubação nitrogenada em cobertura.

Santos et al. (2005) consideram que no primeiro ano de cultivo em sistema orgânico a produtividade é geralmente inferior a do sistema convencional, concordando com o presente trabalho, que com a aplicação de altas doses de esterco mesmo concentrada na linha de semeadura não foi suficiente para garantir produtividades superiores, porém mantendo produtividades semelhantes a adubação química convencional, embora alguns autores recomendem a utilização da dose de 40,0 $\mathrm{t} \mathrm{ha}^{-1}$ incorporados em área total para manter altas produtividades (KONZEN; ALVARENGA, 2002). Silva et al. (2008), afirmam que em grandes áreas cultivadas organicamente, a adubação com composto orgânico é considerada de uso restrito, pois gera grandes problemas de execução, como à forma de aplicação e a quantidade. Visando reduzir a quantidade de adubo orgânico aplicado na semeadura, podem ser adotadas práticas como aplicação do adubo orgânico concentrado na linha, ao invés de distribuídos em área total bem como adição de adubação mineral em cobertura.

Silva et al. (2008), estudando duas variedades de milho em Minas Gerais, verificaram que a adubação orgânica apresentou valores de produtividade próximas em relação aos tratamentos orgânicos (40,0 $\mathrm{m}^{3}$ ha-1 de esterco) com adição de adubação química no plantio $\left(40,0 \mathrm{~m} 3 \mathrm{ha}^{-1}\right.$ de esterco +600 $\mathrm{kg} \mathrm{ha}^{-1}$ de 4-14-8 de NPK $+200 \mathrm{~kg} \mathrm{ha}^{-1}$ de sulfato de amônio em cobertura). Afirmam ainda que para que a adubação orgânica tenha efeitos significativos na produtividade, se faz necessário à aplicação da adubação orgânica por vários anos, pois seu efeito é maximizado a longo prazo, promovendo melhorias na fertilidade do solo, além de proporcionar condições físicas adequadas ao desenvolvimento da cultura do milho.
A adubação química proporcionou uma produtividade de $2463 \mathrm{~kg} \mathrm{ha}^{-1}$ na ausência da adubação em cobertura, e quando aplicou-se $\mathrm{N}$ em cobertura a produtividade foi $2388 \mathrm{~kg} \mathrm{ha}^{-1}$. Substituindo estas produtividades nas equações obtidas (Figura 3) observa-se que para se obter as mesmas produtividades da adubação química seriam necessários 50,1 tha-1 de esterco sem aplicação de $\mathrm{N}$ em cobertura e 45,5 tha-1 de esterco com aplicação de $80 \mathrm{~kg} \mathrm{ha}^{-1}$ de $\mathrm{N}$ em cobertura. Cancellier et al. (2011) avaliaram populações de polinização aberta em condições de alta e baixa aplicação de $\mathrm{N}$, inclusive com a cultivar BR 106, observando produtividades superiores às encontradas no presente estudo, porém a época de plantio utilizada (novembro) pode ter favorecido uma melhor distribuição hídrica para a cultura com relação a épocas mais tardias de plantio como a utilizada neste trabalho.

Para a massa verde, os valores obtidos foram 26,9 e $24,1 \mathrm{t} \mathrm{ha}^{-1}$ de massa verde respectivamente para 0 e $80 \mathrm{~kg} \mathrm{ha}^{-1} \mathrm{de} \mathrm{N}$ em cobertura, sendo equivalente as doses de 62,6 e 2,4 $\mathrm{tha}^{-1}$ de esterco bovino aplicado na linha de semeadura.

Silva et al.(2007), não observaram diferença entre a adubação orgânica e associação entre orgânico e mineral, porém divergências nessas condições pode ser resultado de diferentes condições experimentais, como tempo de aplicação de esterco no solo e quantidade. Nota-se ainda que ocorreu durante o período de florescimento/polinização e enchimento de grão um estresse hídrico (Figura 4) a partir de $01 / 05$, justificando a baixa produtividade média dos tratamentos encontrado neste trabalho, porém, sem impedir a observação do efeito das doses de esterco nas duas condições de adubação em cobertura. Segundo Storck et al. (2009), a ocorrência de deficiência hídrica na cultura do milho durante o período de florescimento pode ocasionar reduções drásticas no rendimento da cultura que podem ultrapassar a $80 \%$ da produtividade de grãos. 


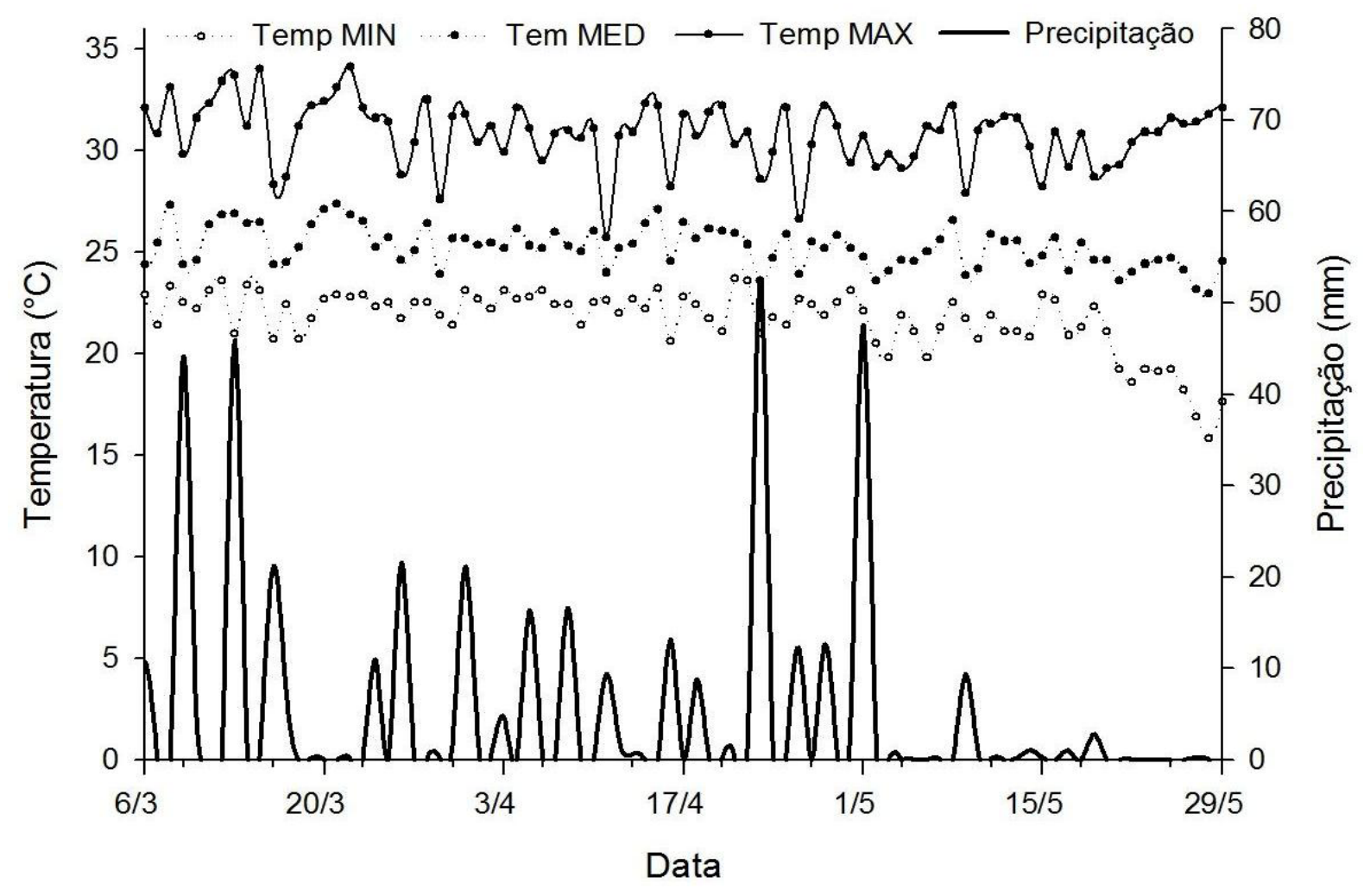

Figura 4. Dados de precipitação, temperaturas mínima, média e máxima de 6 de março a 29 de maio de 2009 em Gurupi, TO.

\section{Conclusões}

O nitrogênio em cobertura promoveu aumentos nas taxas de crescimento de plantas e na produção de massa verde e altura final de plantas, mesmo com adição de adubação orgânica.

A aplicação de 50 t ha $^{-1}$ de esterco sem aplicação de cobertura mostrou produtividade equivalente à adubação química, enquanto com aplicação de $\mathrm{N}$ em cobertura a dose de esterco equivalente foi 45,4 $\mathrm{t} \mathrm{ha}^{-1}$.

Quando não aplicou-se adubação nitrogenada em cobertura, a adubação química produziu massa verde e grãos equivalente as maiores doses de esterco, porém na aplicação de $\mathrm{N}$ em cobertura as maiores doses de esterco proporcionaram produtividades significativamente superiores a adubação química.

\section{Referências}

BALBINOT JUNIOR, A. A.; FLECK, N. G. Manejo de plantas daninhas na cultura de milho em função do arranjo espacial de plantas e características dos genótipos. Ciência Rural, Santa Maria, v. 35, n. 1, p. 245-252, 2005.

BÄNZIGER, M.; EDMEADES, G. O.; LAFITTE, H. R. Selection for drought tolerance increases maize yields across a range of N levels. Crop Science, v. 39, n. 4, p. 1035-1040, 1999.

BEGNA, S. H.; HAMILTON, R. I.; DWYER, L. M.; STEWART, D. W.; CLOUTIER, D.; ASSEMAT, L.; FOROUTAN-POUR, K.; SMITH, D. L. Morphology and yield response to weed pressure by corn hybrids differing in canopy architecture. European Journal of Agronomy, Córdoba, v. 14, n. 4, p. 293-302, 2001.

BREDEMEIER, C.; MUNDSTOCK, C. Regulação da absorção e assimilação do nitrogênio nas plantas. Ciência Rural, Santa Maria, v. 30, n. 2, p. 365-372, 2000.

CANCELLIER, L. L.; AFFÉRRI, F. S.; CARVALHO, E. V.; DOTTO, M. A.; LEÃO, F. F. Eficiência no uso de nitrogênio e correlação fenotípica em populações tropicais de milho no Tocantins. Revista Ciência 
Agronômica, Fortaleza, v. 42, n. 1, p. 139-148, 2011.

CANTARELLA, H. Calagem e adubação do milho. In: BUL, L. T.; CANTARELLA, H. (Ed.). Cultura do milho: fatores que afetam a produtividade. Piracicaba: POTAFOS, 1993. p. 147-198.

COMPANIA NACIONAL DO ABASTECIMENTO CONAB. Série histórica. Comparativo de área, produção e produtividade. Disponível em: $<$ http://www.conab.gov. br/conabweb/index.php? $\mathrm{PAG}=131>$. Acesso em: 18 mar. 2009.

DUARTE, J. O. Importância econômica. In: Cultivo do milho. Embrapa milho e sorgo. Disponível em: $<$ http:// sistemasdeproducao.cnptia.embrapa.br/FontesHTML/ Milho/Cultivo doMilho/importancia.htm>. Acesso em: 20 out. 2008 .

FAGERIA, N. K.; SANTOS, A. B.; STONE, L. F. Manejo de nitrogênio em arroz irrigado. Santo Antônio de Goiás: EMBRAPA, 2003. (Circular técnica, 58).

FERNANDES, E. C.; MOTAVALLI, P. P.; CASTILLA, C.; MUKURUMBIRA, L. Management control of soil organic matter dynamics in tropical land-use systems. Geoderma, Tucson, v. 79, n. 1, p. 49-67, 1997.

FIDELIS, R. R.; MIRANDA, G. V.; SANTOS, I. C.; GALVÃO, J. C. C.; PELUZIO, J. M.; LIMA, S. O. Fontes de germoplasma de milho para estresse de baixo nitrogênio. Pesquisa Agropecuária Tropical, Goiânia, v. 37, n. 3, p.147-153, 2007.

KONZEN, E. A.; ALVARENGA, R. C. Cultivo do milho: adubação orgânica. Sete Lagoas: EMBRAPA, 2002. (Comunicado técnico, 54).

LEITE, L. F. C.; MENDONÇA, E. S.; NEVES, J. C. L.; MACHADO, P. L. O. A.; GALVÃO, J. C. C. Estoques totais de carbono orgânico e seus compartimentos em argissolo sob floresta e sob milho cultivado com adubação mineral e orgânica. Revista Brasileira Ciências do Solo, Viçosa, v. 27, n. 5, p. 821-832, 2003.

MAIA, C. E.; CANTARUTTI, R. B. Acumulação de nitrogênio e carbono no solo pela adubação orgânica e mineral contínua na cultura do milho. Revista Brasileira de Engenharia Agrícola Ambiental, Campina Grande, v. 8, n. 1, p. 39-44, 2004.

MELO, R.; NORNBERG, J. L.; ROCHA, M. G. Potencial produtivo e qualitativo de híbridos de milho, sorgo e girassol para ensilagem. Revista Brasileira de Agrociência, Pelotas, v. 10, n. 1, p. 87-95, 2004.

MENESES, O. B. Efeitos de doses de esterco no rendimento do feião-de-corda e do milho em cultivos isolados e consorciados. 1993. Dissertação (Mestrado em Agronomia) - ESAM. Escola Superior de Agricultura de Mossoró, Mossoró.

MORELlO, C. L.; PELUZIO, J. M.; COELHO, R. M. S.; SANTOS, M. X. Performance de populações de milho (Zea mays L.) em terras altas sob cerrado no centro-sul do estado do Tocantins, Brasil. Acta Amazonica, Manaus, v. 32 , n. 1 , p. 21-31, 2002.

OELSEN, T.; MOLDRUP, P.; HENRIKSEN, K. Modeling diffusion and reaction in soils: VI. Ion diffusion and water characteristics in organic manure-amended soil. Soil Science, Philadelphia, v. 162, n. 6, p. 399-409, 1997.

SAMPAIO, E. V. S. B.; OLIVEIRA, N. M. B.; NASCIMENTO, P. R. F. N. Eficiência da adubação orgânica com esterco bovino e com Egeria densa. Revista Brasileira Ciência do Solo, Viçosa, v. 31, n. 5, p. 995-1002, 2007.

SANTOS, I. C.; MIRANDA, G. V.; MELO, A. V.; MATTOS, R. N.; OLIVEIRA, L. R.; LIMA, J. L.; GALVÃO, J. C. C. Comportamento de cultivares de milho produzidos organicamente e correlações entre características das espigas colhidas no estádio verde. Revista Brasileira de Milho e Sorgo, Sete Lagoas, v. 4, n. 1, p. 45-53, 2005.

SILVA, J.; LIMA E SILVA, P. S.; OLIVEIRA, M.; BARBOSA E SILVA, K. M. Efeito de esterco bovino sobre os rendimentos de espigas verdes e de grãos de milho. Horticultura Brasileira, Brasília, v. 22, n. 2, p. 326-331, 2004.

SILVA, R. G.; GALVÃO, J. C. C.; MIRANDA, G. V.; SILVA, D. G.; ARNHOLD, E. Produtividade de milho em diferentes sistemas produtivos. Revista Verde, Mossoró, RN, v. 2, n. 2, p. 136-141, 2007.

SIlVA, R. G.; GALVÃO, J. C. C.; MIRANDA, G. V.; SILVA, D. G.; ARNHOLD, E. Produtividade de variedades de milho nos sistemas de cultivo orgânico e convencional. Caatinga, Mossoró, v. 21, n. 3, p. 78-85, 2008 .

STEVENSON, F. J. Humus chemistry. Hoboken, NJ: Somerset, John Wiley and Sons, 1982.

STORCK, L.; CARNELUTTI FILHO, A.; LOPES, S. J.; TOEDE, M. SILVEIRA, T. R. Duração do subperíodo semeadura-florescimento, crescimento e produtividade de grãos de milho em condições climáticas contrastantes. Revista Brasileira de Milho e Sorgo, Sete Lagoas, v. 8 n. 1, p. 27-39, 2009.

TRAN, T. S.; NÍDAYEGAMIYE, A. Longterm effects of fertilizers and manure application on the forms and availability of soil phosphorus. Canadian Journal of Soil Science, Ottawa, v. 75, n. 3, p. 281-285, 1995. 
ZHANG, H.; HARTGE, K. H.; RINGE, H. Effectiveness of organic matter incorporation in reducing soil compactibility. Soil Science Society of American Journal, Madison, v. 61, p. 239-245, 1997. 
